\title{
Annotations
}

\author{
Abbreviations
}

\section{Relationship terms}

\begin{tabular}{llll}
\hline M & mother & +nie & cross niece \\
$\mathrm{F}$ & father & $\mathrm{e}$ & older \\
$\mathrm{Z}$ & sister & $\mathrm{y}$ & younger \\
$\mathrm{B}$ & brother & $(\mathrm{ws})$, o $\mathrm{sp}$. & woman/female speaking \\
$\mathrm{D}$ & daughter & $(\mathrm{ms})$, o $\mathrm{sp}$. & man/male speaking \\
$\mathrm{S}$ & son & $\mathrm{y}+\mathrm{cou}$ & younger cross cousin \\
$\mathrm{W}$ & wife & $\mathrm{e}+\mathrm{cou}$ & older cross cousin \\
$\mathrm{H}$ & husband & $\mathrm{y} / / \mathrm{cou}$ & younger parallel cousin \\
$\mathrm{P}$ & parent & $\mathrm{e} / / \mathrm{cou}$ & older parallel cousin \\
$\mathrm{Ch}$ & child/children & $+2,(+2)$ & grandparents' generation \\
sib & sibling & $+1,(+1)$ & parents' generation \\
$\mathrm{sp}$ & spouse & 0 & ego's generation \\
nep & nephew & $-1,(-1)$ & children's generation \\
$/ /$ nep & parallel nephew & $-2,(-2)$ & grandchildren's generation \\
+ nep & cross nephew & os & opposite sex \\
nie & niece & $\mathrm{ss}$ & same sex \\
$/ /$ nie & parallel niece & & \\
\hline
\end{tabular}

\section{Combined relationship terms}

\begin{tabular}{ll}
\hline eBW & older brother's wife \\
MBDy & mother's brother's daughter, younger than ego \\
spsibsp & spouse's sibling's spouse \\
sibspsib & sibling's spouse's sibling \\
HMeB & husband's mother's older brother \\
\hline
\end{tabular}

\section{Abbreviations: social and political}

mmc miyad mandi chaturenko - the people of one rice pot. This specific social Ho unit has been discussed in chapter 3. The abbreviation $m m c$ is frequently recurred to throughout the book.

TRTC Tribal Research and Training Centre

BJP Bharatiya Janata Party (established in 1980; Narendra Modi has been Prime Minister since May 2014) 


\begin{tabular}{llll}
\hline ST & Scheduled Tribe & OBC & Other Backward Classes \\
SC & Scheduled Caste & BPL & Below Poverty Line \\
\hline
\end{tabular}

\section{Abbreviations: linguistic and other}

\begin{tabular}{llll}
\hline pass. & passive voice & refl. & reflexive voice \\
tr. & transitive & $\mathrm{Hi}$ & Hindi \\
itr. & intransitive & $\mathrm{U}$ & Urdu \\
\hline
\end{tabular}

cf. confer; reference to word or material related to topic under discussion with opposite or contrasting meaning

see also reference to word or material related to topic under discussion with similar meaning see reference to other sources of information

E.M. Encyclopaedia Mundarica by Hoffmann, John et al. 1990 [1950]. 16 volumes. New Delhi: Gian Publishers.

ALD Crowther, Jonathan (ed.) 1995. Oxford Advanced Learner's Dictionary 1995. Oxford: Oxford University Press. $5^{\text {th }}$ edition.

\section{Notes on transliteration and formal remarks}

Spelling and denotation of the Ho terms have been checked with Deeney's HoEnglish Dictionary (one volume) from 2005 [1978]. In this Deeney has rendered Ho vocabulary in Roman script and a slightly modified Devanagari taking into account that Ho does not know aspirated consonants and is not identical with Mundari or Munda in terms of grammar and vocabulary despite a high degree of correspondence.

Ho terms and the very few Santali expressions that I make use of in this book are italicized. The names of persons (Lako Bodra), of geographical sites and localities (Chota Nagpur Plateau, Chaibasa), of communities (Gau, Pano), of clans (Purty, Kisku) and subclans (Doraiburu Bodra), of languages (Santali, Kui) and of Sinbonga are capitalized, but not italicized. Following Deeney (2005), the names of Ho deities/spirits (desauli) and of Ho/Gau/Santal festivals (mage, gowa bonga, sohrae) are italicized, but not capitalized.

The Roman script is used throughout for Ho words largely neglecting diacritic marks except where these are phonemic (jati, jati). The colon (:) indicates a glottalized vowel. The check is always given, the length of a vowel only when it is phonemic (goe: versus gōe:). I refer to Ho and Santal people as Ho and San- 
tal in the singular and plural without adding the English plural s-marker. Where necessary the Ho plural marker -ko is suffixed to a noun.

Single quotation marks indicate that the English expressions are considered culturally inadequate, misleading, or narrowing the meaning of the concepts indigenously implied in the terms (haga-'brother'). Double quotation marks come with quotations from oral communication or literary sources.

As a rule, the denotations of indigenous terms are given as they arise. This is repeated throughout the book to improve the readability of the text. Exceptions are frequently used Ho terms when the context allows to do so. This concerns especially the following terms:

\begin{tabular}{llll}
\hline adin & inner room of a house; abode of the & ham ho- & old men/ sleeping men; the dead \\
forefathers' souls; during festivals meals & dum & of the house whose spirits/ souls \\
are prepared inside & hoko & dwell in the adin \\
dewa & shaman & munda & village headman \\
diuri & ritual guide & bonga & a spirit; to sacrifice \\
diyan & rice-beer & haga & 'brother', brother \\
\hline
\end{tabular}

In Glossary II the denotations of many Ho terms that have been used in the body of the text have been contextualized and complemented, where considered insightful, by term-related references to fieldwork and brief comments.

A separate glossary I with notes on Ho history concerns the situation on the Chota Nagpur Plateau during the colonial and precolonial period. It provides background information complementary to that given in the main body of the text. Browsing through the two annotated glossaries first before reading the book may be an idea for some to become preliminarily acquainted with a few notions, perspectives, and specifics of Ho people and the world they live in.

I have been given permission by all informants to make use of our conversations, their names, and the names of their villages. They also agreed to having the photos published. 
